\title{
Design and testing of a supercapacitor storage system for the flash recharge of electric buses
}

\section{Luca Pugi*}

Department of Industrial Engineering,

University of Florence,

Via di Santa Marta 3, 50139 Firenze, Italy

Email: luca.pugi@unifi.it

${ }^{*}$ Corresponding author

\section{Adriano Alessandrini}

University of Florence,

Department of Civil and Environmental Engineering,

Via di Santa Marta 3, 50139 Firenze, Italy

Email: adriano.alessandrini@unifi.it

\section{Riccardo Barbieri, Lorenzo Berzi and Marco Pierini}

Department of Industrial Engineering,

University of Florence,

Via di Santa Marta 3, 50139 Firenze, Italy

Email: riccardo.barbieri@unirfi.it

Email: lorenzo.berzi@unifi.it

Email: marco.pierini@unifi.it

\section{Fabio Cignini, Antonino Genovese and Fernando Ortenzi}

ENEA-Ente Per Le Nuove Tecnologie,

l'Energia e l'Ambiente,

C.R. ENEA Casaccia - Via Anguillarese 301,

00123 Roma (RM), Italy

Email: fabio.cignini@enea.it

Email: antonino.genovese@enea.it

Email: fernando.ortenzi@enea.it

\begin{abstract}
This paper proposes a hybrid storage for urban transport systems in order to reduce recharge time and increase its life and reliability. Proposed system is applied to a pre-existing electric vehicle, introducing through proposed revamping procedure a methodology for a fast integration of proposed systems on different vehicles. Finally, the system is calibrated and tested showing how the proposed control layout really simplifies the vehicle commissioning.
\end{abstract}


Keywords: hybrid storage systems; electrification; fast recharge; super capacitors; mechatronics; traction systems; electric powertrain.

Reference to this paper should be made as follows: Pugi, L., Alessandrini, A., Barbieri, R., Berzi, L., Pierini, M., Cignini, F., Genovese, A. and Ortenzi, F. (2021) 'Design and testing of a supercapacitor storage system for the flash recharge of electric buses', Int. J. Electric and Hybrid Vehicles, Vol. 13, No. 1, pp.57-80.

Biographical notes: Luca Pugi obtained his Masters degree in Mechanical Engineering in 1999 at the University of Florence. In 2003, he gained his $\mathrm{PhD}$ in Applied Mechanics at the University of Bologna (Italy). He is currently working at the University of Florence where he is responsible for courses dealing with mechatronics, actuation and propulsion systems, applied mechanics. He is co-author of more than 200 indexed publications dealing with various applications of mechatronics to different industrial applications. He is also co-founder of two spin-off companies of Florence University.

Adriano Alessandrini is Mechanical Engineer with $\mathrm{PhD}$ in Energy Technologies. He is currently an Associate Professor of Transportation (ICAR-05) at the University of Florence. Since 1998, he has participated in more than 30 research projects, including the founding project of the Centre for Transport and Logistics of the University of Rome La Sapienza (CTL). His main research interests are the environmental impact of vehicles and automated transport systems. He was shortlisted twice 2014 and 2016 for EU Champion of Transport Research prize. In 2015, he served as Evaluator for The National Cooperative Highway Research Program (NCHRP).

Riccardo Barbieri obtained his degree in Management Engineering with a thesis on process optimisation for the Public Administration in 2009 at the University of Florence. In 2010, he started his PhD course in the research field of Alternative Mobility such as electric vehicles and wireless power transfer technologies. In 2013, he started a Post-doc collaboration with the Università degli Studi di Firenze on the topics of sustainable mobility, both vehicle design and feasibility analysis for new technologies' introduction in urban areas. He currently works as Research Engineer in the Moving group since 2016 taking care of sustainable mobility.

Lorenzo Berzi obtained his Master degree in Mechanical Engineering at the University of Florence in 2008. In 2013, he received a $\mathrm{PhD}$ in Industrial Engineering, defending the thesis: "Design methods for modern electric and hybrid electric vehicles: concept design and context analysis". His current research activities concern several areas: vehicle modelling and simulation, powertrain electrification, driving cycle analysis and synthesis, vehicle energy management, end-of-life-vehicles management, material recycling, process modelling and simulation. He has been involved in some project: IMPROVE, ASTERICS, VECOM, REAUTO, OBELICS.

Marco Pierini is an Associate Professor at the Department of Mechanics and Industrial Technologies, Università degli Studi di Firenze. He is head and co-founder of the Research Centre for Innovation and Safety of Powered Two-Wheelers. He has 20 years of experience in transport research with special focus on road safety, $\mathrm{NVH}$, urban and interurban mobility. His research activity 
is mainly focused on various aspects of road vehicles and mobility. He has been responsible for more than 20 project at EU, National and regional level. $\mathrm{He}$ is responsible of the PhD school in Development of Industrial Products and Processes.

Fabio Cignini is currently works at ENEA research centre dept. DUEE (Energy Efficiency). He does research in Automotive Systems Engineering, Automated Road Transport Systems, Low Emission Trasnsport Systems, Engineering and Automotive Engineering. He obtained his degree in 2013 and $\mathrm{PhD}$ in 2019 at the University of Roma-Sapienza discussing his research activities on hybrid and electric powertrains.

Antonino Genovese, Master's degree in Electronic Engineering; senior researcher at ENEA (Italian National Agency for New Technologies, Energy and Sustainable Economic Development). He is former Adjunct Professor in Electronics at Campus BioMedico of Rome University from 2002-2012. He is project manager in Electric Mobility Project as part of Research Program on the Electric Grid System from 2013 to 2017. He is Head of ENEA Laboratory "Technologies and systems for sustainable mobility" from 2018. He is member of Scientific committee of CITraMS (Interdepartmental Center for Transport and Sustainable Mobility - L'Aquila University).

Fernando Ortenzi is currently a researcher DTE-PCU-STMA Laboratory (Sistemi e Tecnologie per la Mobilità e l'Accumulo). His main research topics are focused on hybrid and electric powetrains, battery storage, electric vehicles charging infrastructure, fast charge flash charge, wireless charge, and internal combustion engines. He obtained his degree at University of Rome La Sapienza in 2003 where he also discussed his PhD thesis in 2008. From 2008 to 2012, he has worked as research fellow at Centre for Transport and Logistics (CTL) in Rome.

\section{Introduction}

Reliability and durability of electric storage systems are important factors for development of electric transport systems. Prices of lithium storage systems are smoothly decreasing (Naumann et al., 2015) however relative impact of storage system on the cost of electrical vehicle remains quite high, due to a corresponding increase of their size in terms of stored energy and required power specifications (Hannan et al., 2017). The need for fast recharge times and high reliability plays a key role in this sense: in order to reduce recharge times the storage is subjected to high recharge currents, which should produce an accelerated ageing of cells if they are not properly sized as stated by consolidated ageing models proposed in literature (Fernández et al., 2013; Ecker et al., 2012). Consequences in terms of systems are generally the following ones:

- $\quad$ high power cells with lower energy density are preferred to high energy/autonomy ones

- battery storage is a bit bigger with respect to its optimal size in terms of autonomy in order to compensate the adoption of fast partial recharge that is performed to reduce battery ageing 
- a minimum performance of aged storage system has to be assured so the battery is designed to be a bit oversized in order to compensate a capacity fading of about $20 \%$.

Supercapacitors offer superior performances in terms of specific power and are relatively immune to cycle ageing that affects electrochemical batteries (Musolino et al., 2010); however with current available technologies their specific energy ratio and their selfdischarge losses are quite inferior with respect not only to lithium energy but also to lead ones.

It should be concluded that supercapacitors and batteries have currently complementary properties that should be exploited by the so-called hybrid storage systems such as the one proposed by Yu et al. (2016) or by Veneri et al. (2018) in which supercapacitors are adopted to provide high currents during transients while lithium (Yu et al., 2016) or zebra (Vener et al., 2018) batteries assure the autonomy of the vehicle thanks to their high specific energy ratio.

Respect to overcited literature authors focused their attention public transport systems in high populated urban areas.

Typical mission profiles (Barbieri et al., 2016) of urban transport systems are associated to relatively small distances (few hundred metres) between bus stops; so it should be interesting to exploit the limited time available at each bus stop, no more than $100-150 \mathrm{~s}$ to perform a rapid flash recharge of the bus to arrive at least at the next bus stop. Considering high currents involved and the number of resulting charge and discharge cycles, supercapacitors are the ideal solution for this kind of mission profile. However considering the limited amount of energy that can be stored in supercapacitors they have to be helped by a backup battery that assures the necessary resiliency of the system respect to variable mission profiles in which distance or time between bus stops should be variable or perturbed by external traffic conditions. Life and reliability of batteries should be acceptable even adopting a modest highly optimised size since required power profile corresponds to relatively modest currents of small duration.

In this sense proposed application is quite original and innovative with respect to current literature since high power response of the supercapacitor is exploited only during high voltage recharge phase, while during a normal mission profile the battery is designed to substantially supply the main supercapacitor storage with respect to energy limits of supercapacitors and power limits of adopted DC-DC converters.

Hybridisation of supercapacitor storage with a battery is also exploited to drastically simplify the way in which the system is controlled producing a simple and robust control loop that can be implemented and calibrated with limited computational resources.

This is not the only original contribution of the research because a passive system for the recharge station based on supercapacitors is also proposed.

Finally, in order demonstrate feasibility of proposed solution we produce a low-cost prototype by revamping a pre-existing electric bus. This was also the occasion to demonstrate that proposed system, thanks to its robustness and simplicity, can be easily customised and calibrated for different vehicles. 


\section{General design and conception of the proposed system}

As visible in the scheme of Figure 1, the system is composed by a set of supercapacitors that are directly connected to the recharge station which is supposed to be installed at the bus stop. Since a high amount of power has to be transferred in few seconds, supercapacitor modules are assembled in order to be charged at a voltage which is much higher with respect to the one of the DC bus in order to reduce the amount of current that is collected from pantograph head and more generally conducting sections.

Figure 1 Simplified scheme of proposed hybrid storage system (see online version for colours)

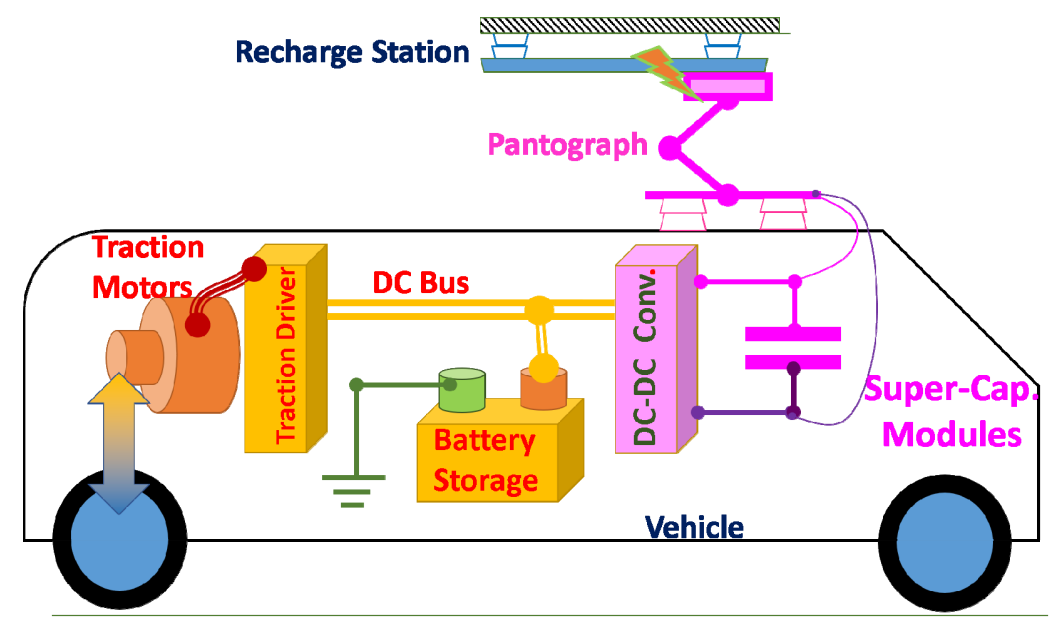

Also a higher operating voltage simplifies the layout of the chopper used to interface supercapacitors which is fundamentally a two quadrant power converter which should be further simplified to a single quadrant one considering that the the proposed converter has to work mainly as simple buck, step down chopper.

DC bus of the traction system is also stabilised by a battery which is fundamentally a downsized version of the storage system that should be installed on a standard electric vehicle in which the flash recharge system is not installed.

Since specific energy of the battery is much higher than the one the battery assures a reserve of power which should be used if the limited amount of energy available on supercapacitors is depleted, assuring a significant resiliency and residual autonomy of the vehicle. Also, battery is useful to optimise the sizing of DC-DC converters that are interfacing super-capacitor to DC bus since peak currents that cannot be managed by the chopper are also sustained by the battery.

Considering that most of the energy during a normal mission is provided by supercapacitors, during a standard mission the battery is subjected to very limited currents and discharge rates, so a relatively long life of the energy storage system is feasible.

For the system control loop, a very simple, self-compensating strategy is chosen. 
As visible in Figure 2, a fixed desired battery current $I_{\text {ref }}$ is chosen; the current which is effectively supplied by the battery $I_{\text {meas }}$ is measured using a redundant sensor system (only for a purpose of safety and system reliability).

Figure 2 Proposed control loop (see online version for colours)

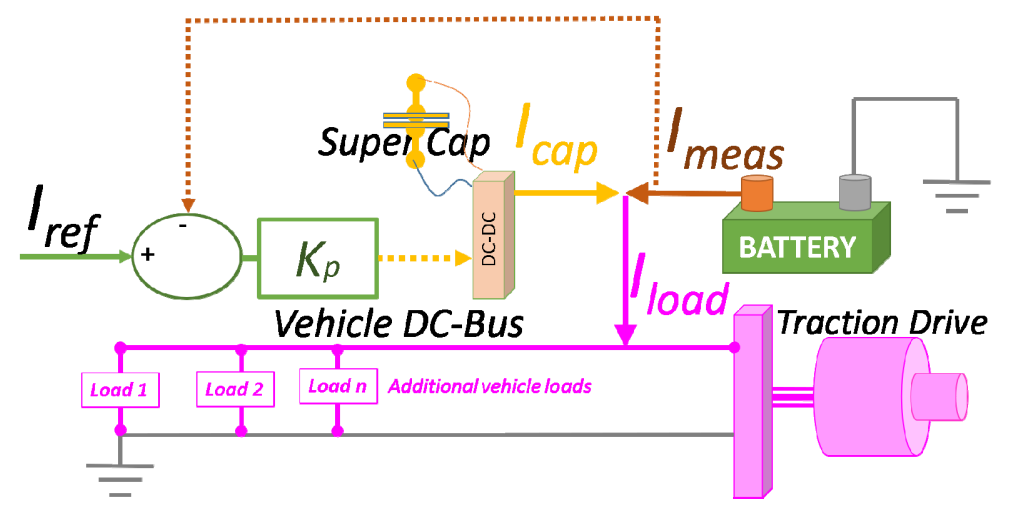

A closed loop current controller is used to assure that the battery current $I_{\text {meas }}$ is close as possible to desired value $I_{\text {meas }}$ by imposing to DC-DC choppers a compensating current $I_{\text {cap }}$ which is drawn from supercapacitors.

In this way, the current required by connected loads $I_{\text {load }}$ is automatically compensated as a rejected disturbance without the need of any complex prediction or measurement of applied loads.

As example by considering a simple proportional controller with gain $K_{p}$ balance has to be verified and the steady state ratio between load current and the corresponding contributions of battery and supercapacitors can be easily evaluated.

Gain $K_{p}$ and value of $I_{r e f}$ can be scheduled with respect to other system states such as example battery state of charge, capacitor state of energy, error between reference current $I_{\text {ref }}$ and measured one $I_{\text {meas }}$.

This servo-control scheme is very robust with respect to bandwidth limits which are compensated by the battery; implementation and tuning are quite easy(for a proportional controller only one gain scheduling should be inserted as an additional feature); the proposed solution can be easily adapted to different vehicle and traction systems since the proposed power management algorithm works only on internal measurements requiring a very limited interfacing with the traction system of the vehicle since only DC bus is shared.

\subsection{Pantograph on vehicle vs. pantograph on recharge station}

Electrical contact between recharge stations and vehicles must be performed using a pantograph system that is specifically designed to assure a correct electro-mechanical contact compensating unavoidable tolerances in relative positioning between vehicle and recharge station. 
In literature two possible solutions are proposed as visible in the schemes of Figure 3(a) and (b):

- Vehicle pantograph (Becker and Dämmig, 2016): An extendible pantograph is installed on the vehicle, while a fixed contact strip is placed on the recharge station: pantograph is the more expensive components and also the most sensitive in terms of maintenance and failure occurrence. Also weight added to vehicle is much higher respect to a fixed contact strip. On the other hand, maintenance can be easily performed on a single vehicle which can be retired from service but it's relatively more complex to be performed on a public infrastructure as the recharge station without interrupting its service.

- Pantograph on recharge station (https://www.schunk-carbontechnology.com/en/ smart-charging, https:/www.dazetechnology.com/dazeplug/): for what concern vehicle on board systems this solution is much simpler. However as previously said, an increased complication in the management of unmanned recharge stations should be carefully evaluated.

Figure 3 Pantograph on vehicle (a) and pantograph on charging station (b) (see online version for colours)

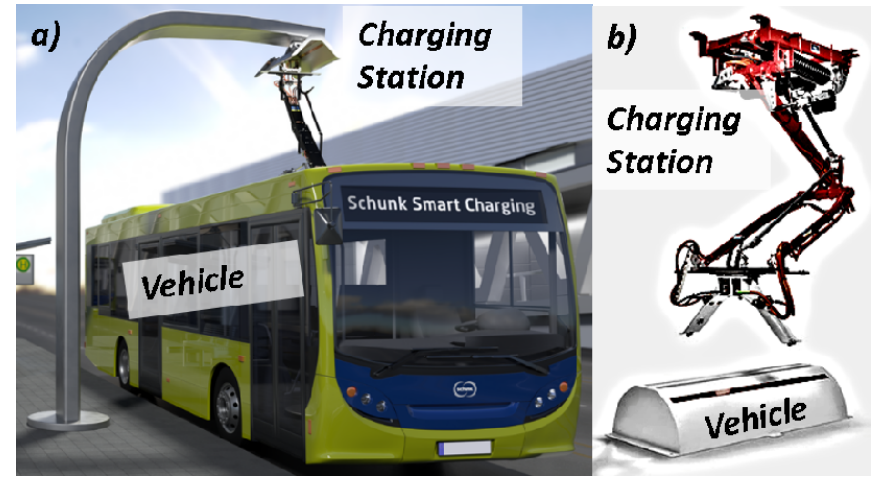

Source: https://www.schunk-carbontechnology.com/en/smart-charging

Proposed hybrid storage can be applied in both cases, however in this work authors have mainly focused their attention on the first solution, pantograph on vehicle.

\subsection{Passive recharge stations with supercapacitors}

Currents involved during a flash recharge should be very high, since as stated by equation (1) a faster recharge (duration of the charge is $T_{\text {charge }}$ ) respect to duration of performed mission $T_{\text {mission }}$ involves a higher mean recharge current $I_{\text {charge }}$ :

$$
\begin{aligned}
& \eta_{\text {mean }} T_{\text {charge }} V_{\text {charge }} I_{\text {charge }}=W_{\text {mean }} T_{\text {mission }} \Rightarrow \\
& \Rightarrow I_{\text {charge }}=\frac{W_{\text {mean }}}{\eta_{\text {mean }} V_{\text {charge }}} \frac{T_{\text {mission }}}{T_{\text {charge }}}
\end{aligned}
$$


Equation (1) also justifies the adoption of high recharge voltages $V_{\text {charge }}$ respect values that really needed to feed the DC bus of the traction system. Mean efficiency $\eta_{\text {mean }}$ is a constant coefficient that should be introduced to take count of the losses introduced by the energy management chain between recharge station and mean electrical power $W_{\text {mean }}$ used by vehicle loads.

According to equation (1), considering maximum current and voltage limits of pantographs, also the distance between two contiguous recharge stations is also constrained by the limited available time for recharge operations.

Also, the electrical interfacing of recharge stations to grid should involve undesirable peaks of power and also involve the management of heavy impulsive currents.

For this reason, in this project it was proposed a passive system originally proposed by ENEA that is described in a dedicated research work which have been recently published (Ortenzi et al., 2019).

The recharge station is composed by an array of series connected supercapacitor modules that can be smoothly charged reducing peak loads on the grid. As the bus approaches the recharge stations these charged supercapacitor modules are gradually connected in series with vehicle ones producing a series of impulsive recharge currents that are smoothed with passive elements such as inductances as visible in the simplified scheme of Figure 4: considering the size of vehicle supercapacitors which should be better described in Section 3 of this work, foreseen duration of recharge system is less than 60-70 s and collected currents are quite tolerable for pantograph system.

Figure 4 Proposed passive recharge station (see online version for colours)
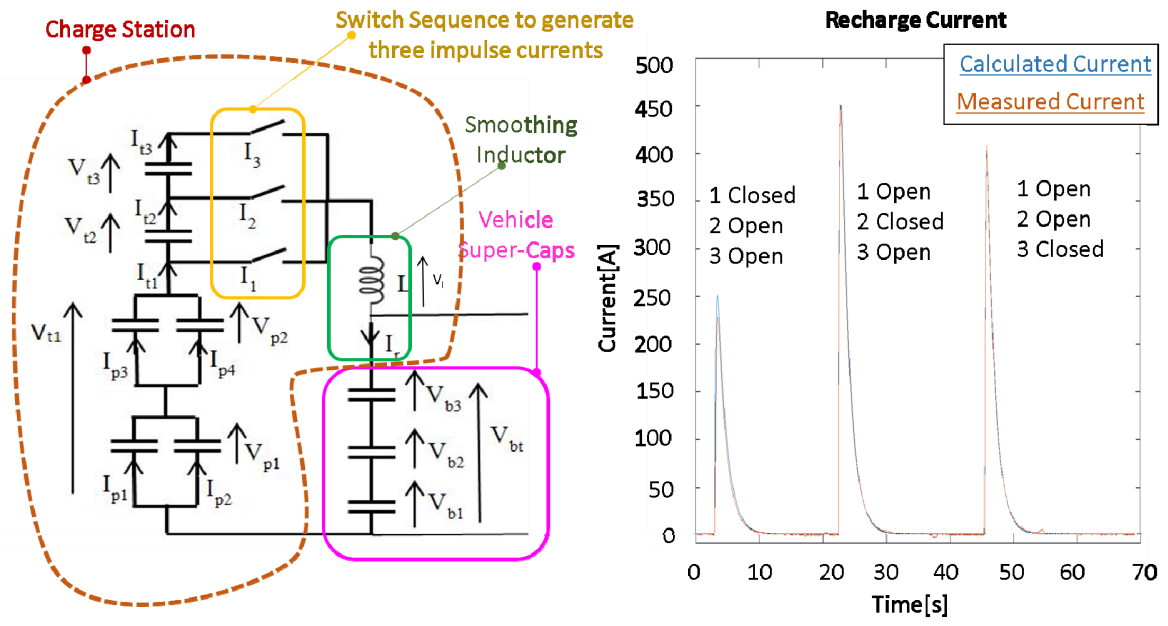

Source: Ortenzi et al. (2019)

\section{Design for a demonstrator vehicle}

In order to verify the feasibility of proposed solutions authors decide to test it on a demonstrator vehicle: a pre-existing electric bus TECNOBUS Gulliver ESP 520, visible 
in Figure 5, was chosen to be revamped and adapted for installation and testing of the proposed system. This vehicle was chosen as benchmark platform for the following reasons:

- $\quad$ cheap and affordable platform, not only vehicle but also components for maintenance are readily available on the market

- $\quad$ mature but well known product; wide databases of recorded mission profiles performed in different Italian cities are available and some of these tests, performed on the route visible in Figure 6, have been performed by some of the authors (Barbieri, et al., 2016).

Vehicle was originally designed for battery swapping of a large lead-acid accumulator; so there was the availability of a large volume, a redundant load capacity, and a modular battery frame that was designed to be easily accessed and moved.

Figure 5 Proposed benchmark vehicle, TECNOBUS Gulliver ESP 520

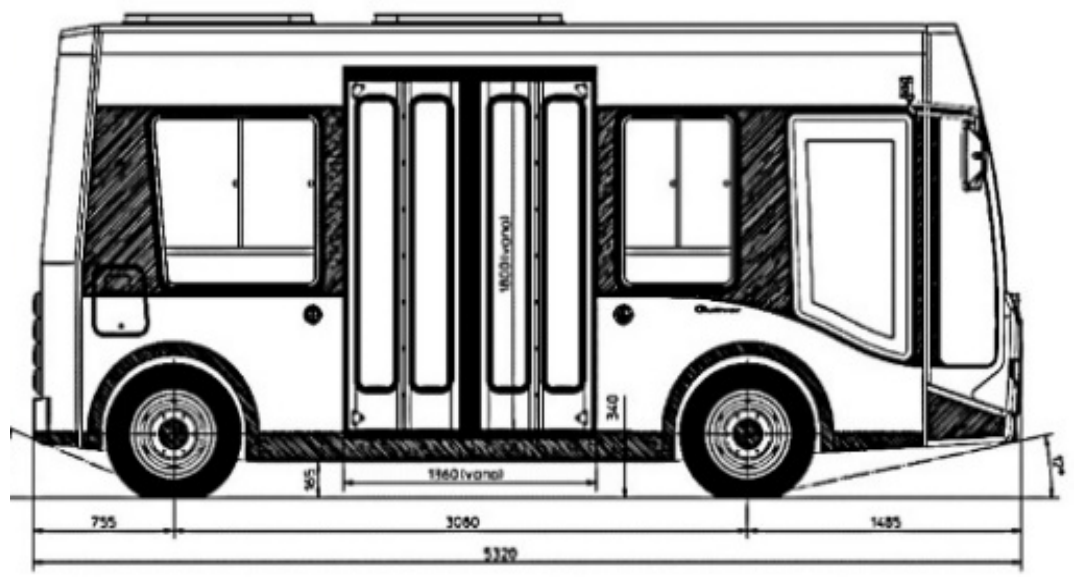

Figure 6 Example of recorded mission profile in Florence (see online version for colours)

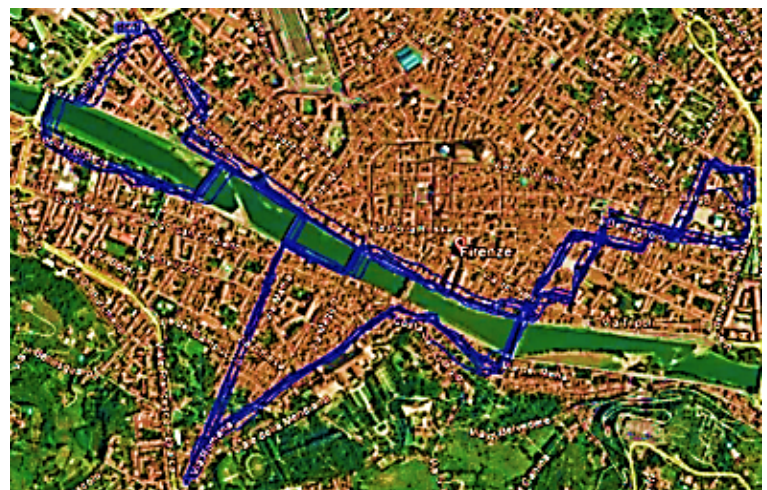

Source: Barbieri et al. (2016) 
Volume once occupied by the original battery frame was substituted as visible in Figure 7 with a modular power unit in which proposed hybrid storage system was installed.

As a part of performed vehicle integration activities, authors also installed on the roof a Schunk pantograph specifically developed for fast static recharge of vehicles at bus stops (https://www.schunk-carbontechnology.com/en/smart-charging). Composite structure of vehicle roof was not originally designed to support the additional mass of the pantograph, so authors designed an internal birdcage structure made with steel pipes which was disguised as an internal handrail for passengers as visible both in Figures 7 and 8 .

Figure 7 Performed mechanical integration of the proposed hybrid energy storage system (see online version for colours)

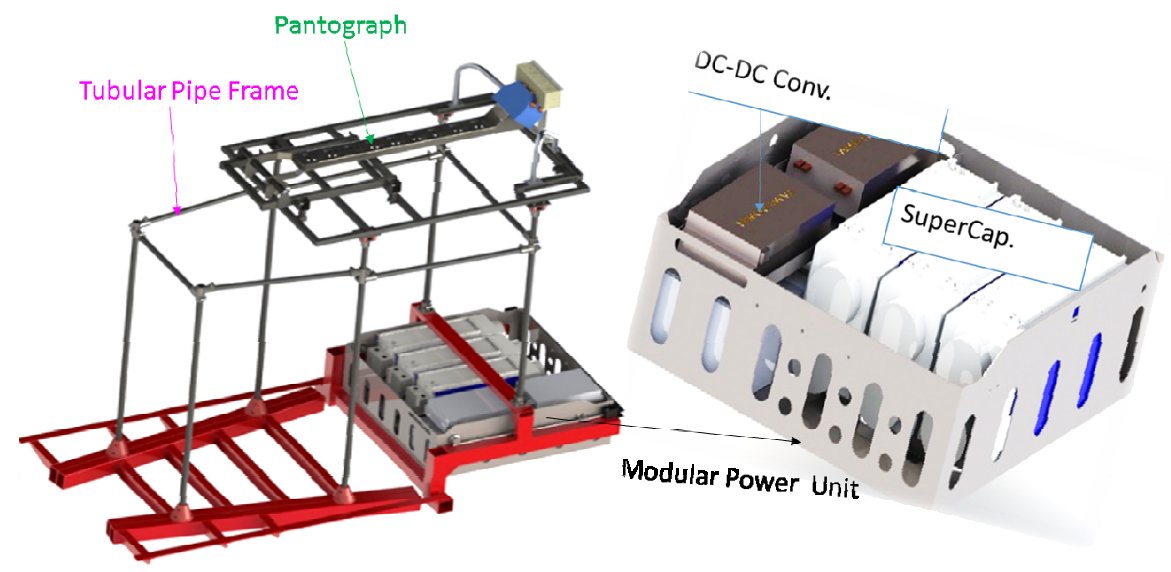

Figure 8 Vehicle-pantograph structural integration (see online version for colours)

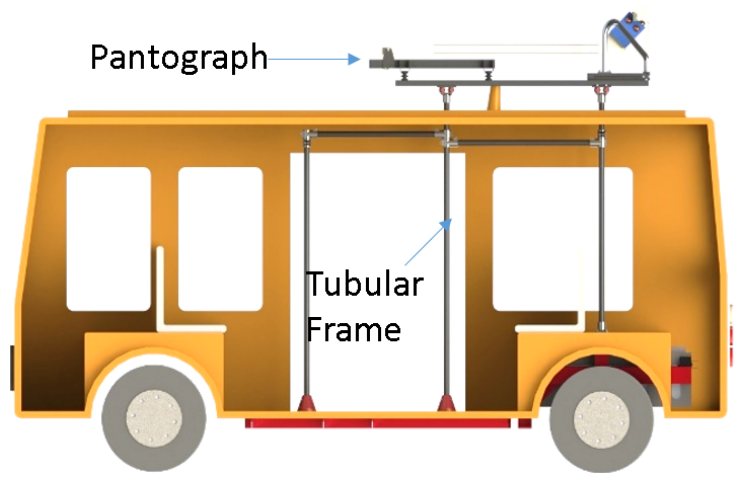

\subsection{Sizing of hybrid storage system}

From experimental data regarding real mission profiles performed by the revamped electrical bus it was possible to understand that energy required to perform the distance between two consecutive bus-stops was variable but confined in a range of values of 200-300 Wh as visible in the examples of Figure 9. For tests in which only vehicle speed profiles were available, corresponding power profiles have been measured by testing the 
vehicle at ENEA of roller rig in the laboratories of Roma Casaccia in Italy: for this reason in the test sequence of Figure 9 duration of bus stops is reduced to $10 \mathrm{~s}$, to accelerate the execution of long mission patterns on the rig.

Figure 9 Speed and energy consumptions (see online version for colours)

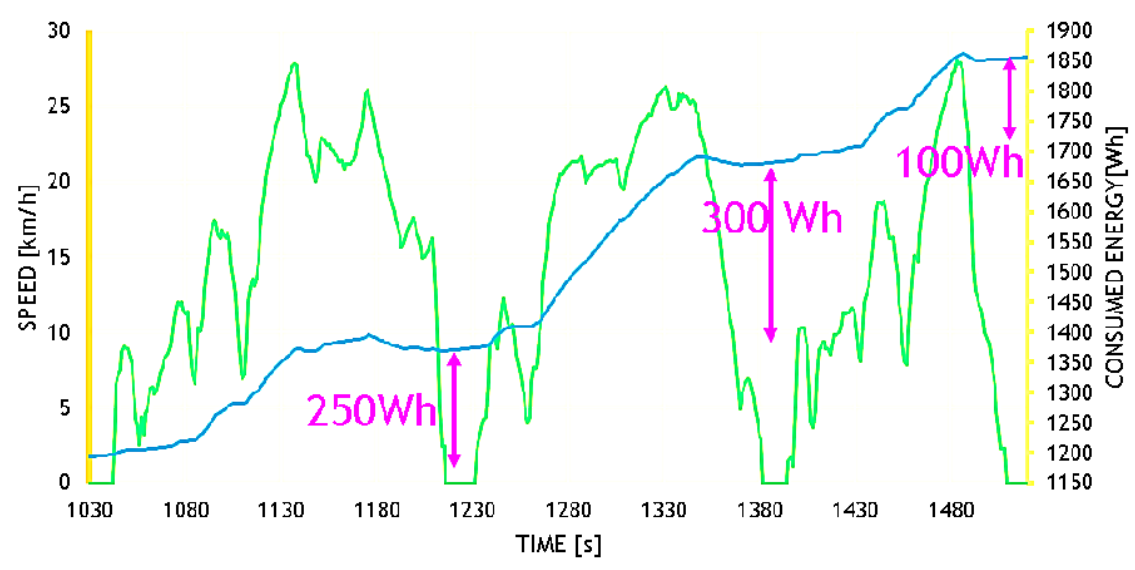

This evaluation was also confirmed by a statistical analysis of the energy needed by the bus to cover one kilometre at various speed as visible in Figure 10. This analysis was also performed in order to verify that to perform a mission of about $500 \mathrm{~m}$. Probably a stored energy between $200 \mathrm{Wh}$ and $300 \mathrm{Wh}$ should be enough since specific consumptions of more than $600 \mathrm{Wh} / \mathrm{km}$ are recorded only for very small vehicle speeds: in this condition consumption of auxiliary systems and inefficient traction transients (braking without regeneration or high accelerations) substantially justifies this behaviour.

Figure 10 Mean specific energy consumptions of vehicle (see online version for colours)

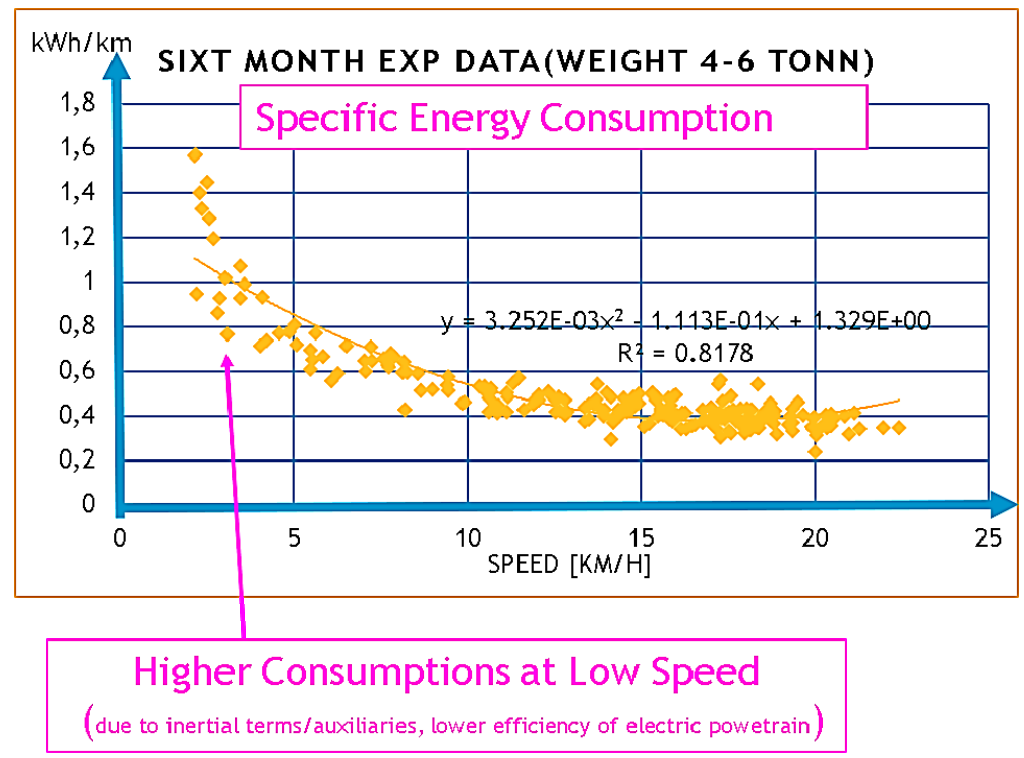


These data were enough to perform the sizing of supercapacitor modules: authors have chosen three Maxwell modules BMOD0063 P125: since each module has a nominal capacity of $63 \mathrm{~F}$ and a nominal voltage of about $125 \mathrm{~V}$, with three modules a total energy of more than $400 \mathrm{Wh}$ can be stored. Chosen capacitor modules were connected in series resulting in a $400 \mathrm{~V}$ system. Series connection was chosen to reduce as much as possible the value of recharge currents as stated by equation (1). In this sense the most important limitation is represented by conducting sections of both pantograph and recharge station which should be easier and cheaper to be designed with higher voltages.

The amount of stored energy by the traction system is greatly affected by some features of the DC-DC converter that is adopted to interface supercapacitors with vehicle DC bus.

Concerning the sizing of this chopper, authors considered a modular system that can be easily sized by putting in parallel a certain number of modules (https://www.tamepower.com/en/dc-dc-converters/dcdc-non-isolated-converters) with a fixed power of about 5-8 kW. In particular, energy $E_{\text {bus }}$ that should be transferred from supercapacitor modules to DC bus is described by equation (2):

$$
E_{\text {bus }}=\frac{1}{2}\left(\max V_{c a p}^{2}-\min V_{c a p}^{2}\right) \eta_{c o n v}
$$

In particular, looking to equation (2), it's clearly noticeable that transferred energy $E_{b u s}$ is not limited only by converter efficiency $\eta_{c o n v}$, assumed for simplicity constant, but also by the value minimum value of capacitor voltage $V_{\text {cap }}$ that can be managed by the DC-DC converter. For chosen TAME DC-DC modules these features are briefly described in Table 1 .

Table 1 Specifications of DC-DC converter modules (https://www.tame-power.com/en/dc-dcconverters/dcdc-non-isolated-converters) (multiple modules are adopted)

\begin{tabular}{lc}
\hline Component parameter & Value \\
\hline DC-DC Converter & COMET Series by TAMETM \\
Weight (one module) & About $11[\mathrm{~kg}]$ \\
Power $(\min / \mathrm{mean} / \mathrm{max})$ & $5 / 6.5 / 8[\mathrm{~kW}]$ dep. on voltage level \\
Efficiency & About $92 \%$ (mean nom. power) \\
Input voltage ratio (Max $\left.V_{\text {cap }} / \operatorname{Min} V_{\text {cap }}\right)$ & About 2 (min $\left.V_{\text {cap }}=200 \mathrm{~V}\right)$ \\
Control Mode & Current Controlled (buck/boost) \\
\hline
\end{tabular}

Starting from a maximum stored energy of about $400 \mathrm{Wh}$ adopted DC-DC modules assure the extraction on the DC bus of an energy $E_{\text {bus }}$ of about 270-280 Wh.

In order to choose the number of DC-DC modules and consequently size the whole power converter authors considered some examples of power profiles visible in Figure 11 that have been measured with ENEA roller rig tests: the first one is an example of typical mission profile from recorded speed profiles, the second one is a test in which maximum vehicle performances both in terms of traction and regenerative braking power are fully exploited. 
Figure 11 Sizing of DC-DC modules respect to simulated mission profiles (see online version for colours)

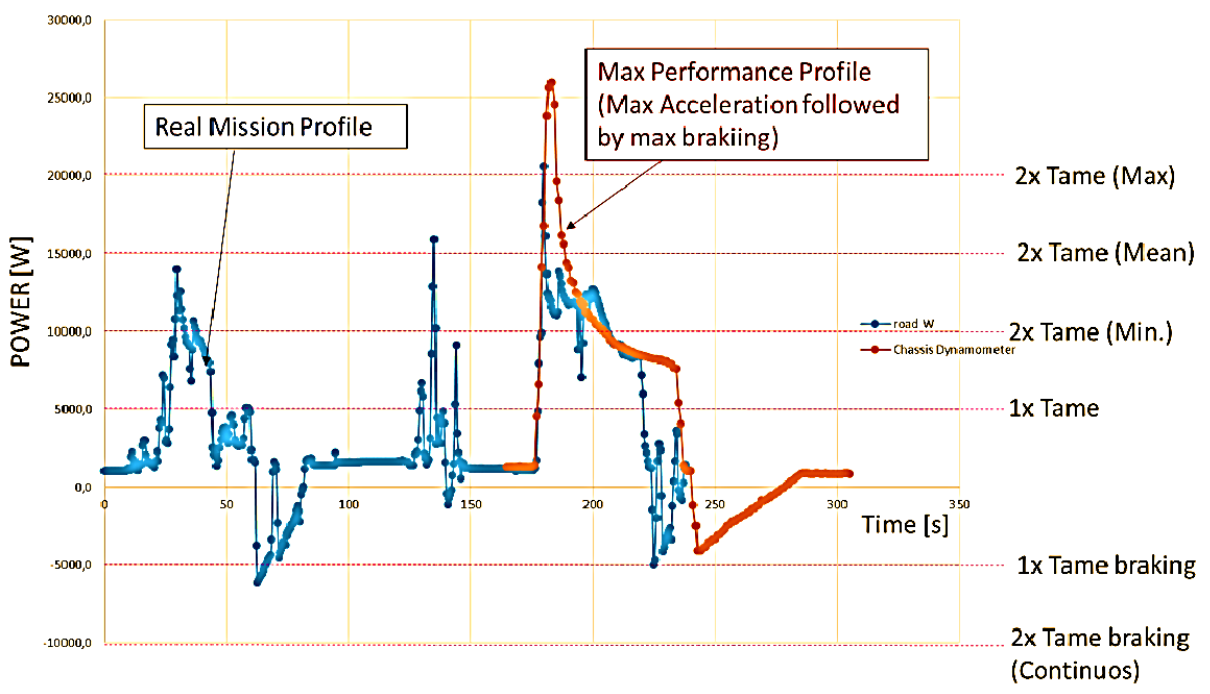

Since supercapacitors are assisted also by batteries there is no-need to size the system for peak power; authors preferred to use a solution of two DC-DC modules in order to assure a power capability between $10 \mathrm{~kW}$ and $20 \mathrm{~kW}$. This variability of power converter performances is due to variability of input voltage provided by super-capacitors, when they are fully loaded $\left(V_{\text {cap }}=400 \mathrm{~V}\right)$ power performance is the maximum one, when they are almost discharged $\left(V_{c a p}=200 \mathrm{~V}\right)$ minimum performances are assured.

This is a normal, feasible behaviour since performance is limited by maximum allowable currents.

This smaller size of the power converter is preferred in order to reduce costs and encumbrances but also to improve system efficiency since higher losses should be foreseen for a converter which is too much oversized when working with partial loads.

Concerning the installed battery the original vehicle was equipped with a $595 \mathrm{Ah} / 72 \mathrm{~V}$ lead acid battery with a total weight of $1500 \mathrm{~kg}$. Thanks to the continuous support of the flash recharge system, the size of the battery was reduced to a $120 \mathrm{Ah} / 72 \mathrm{~V}$ lead acid battery. This choice was justified by the need in the first prototype of reducing cost minimising unnecessary modifications of the system: in particular the new battery assures a weight reduction of about $1200 \mathrm{~kg}$ that allows the installation of the new system on the bus including pantograph and corresponding structural reinforcements without increasing vehicle weight or reducing its load capability.

At the end of the design process main parameters regarding vehicle, supercapacitors, power converters and recharge stations have been summarised in Tables 2-5. In particular capacitors of recharge station described in Figure 4 and in Table 5 have been designed considering the size of vehicle supercapacitors, and the need of limiting the peak values of charging currents. 
Table 2 Vehicle parameters

\begin{tabular}{lc}
\hline \multicolumn{2}{c}{ Vehicle parameters } \\
\hline Weight (Tare/Maximum) & $4270 / 6045[\mathrm{~kg}]$ \\
& Lead Acid/595[Ah] @ $72[\mathrm{~V}] / 1500[\mathrm{~kg}]$ downsized \\
Batteries (kind/capacity/weight) & to $120[\mathrm{Ah}] 270 \mathrm{~kg}$ \\
Inst. traction system (nom. peak power) & $21[\mathrm{~kW}] / 25[\mathrm{~kW}]$ \\
Lights and on board instr. (power) & $200[\mathrm{~W}]$ \\
Air conditioning system & $2[\mathrm{~kW}]$ \\
\hline
\end{tabular}

Table 3 Vehicle super capacitors

\begin{tabular}{ll}
\hline \multicolumn{2}{c}{ Installed super capacitors on vehicle } \\
\hline Model & Three Maxwell BMOD0063 P125 series \\
& connected \\
Weight (one module) & About $60[\mathrm{~kg}]$ \\
Capacity (one module) and resistance & $63[\mathrm{~F}](63-76[\mathrm{~F}])-18[\mathrm{~m} \Omega]$ \\
Test current for capacitance and ESRDC & $100[\mathrm{~A}]$ \\
Rated//maximum voltage (one module) & $125[\mathrm{~V}] / / 136[\mathrm{~V}]$ \\
Max series voltage & $1500[\mathrm{~V}]$ \\
Maximum current (Peak Value) & $1900[\mathrm{~A}]$ \\
\hline
\end{tabular}

Table 4 Vehicle DC-DC power converters

\begin{tabular}{ll}
\hline \multicolumn{2}{c}{ Bi-directional DC-DC converters to interface SuperCapacitors } \\
\hline DC-DC Converter & COMET Series by TAMETM \\
Weight (one module) & About $22[\mathrm{~kg}](11 \mathrm{~kg})$ \\
Power (min $/$ mean $/ \mathrm{max})$ & $5 / 6.5 / 8[\mathrm{~kW}]$ dep. on voltage level \\
Efficiency & About $92 \%$ (mean nom. power) \\
Control Mode & Current Controlled (buck/boost) \\
\hline
\end{tabular}

Table 5 Supercapacitor and smoothing inductance (as sized for current prototype)

\begin{tabular}{lc}
\hline \multicolumn{2}{c}{ Recharge station } \\
\hline Capacitors & Six modules Maxwell BMOD0063 P125 (same data as vehicle one) \\
Smothing Inductor & $4[\mathrm{H}]$ \\
\hline
\end{tabular}

\section{Preliminary testing activities on assembled demonstrator}

\subsection{Fast prototyping of system control logic}

As visible in Figure 12, proposed storage system was preliminary tested in UNIFI laboratories applying a limited load (about one $\mathrm{kW}$ ) to each power converter in order preliminary verify the control of DC-DC converters. For these preliminary tests, vehicle control logic was prototyped in Matlab-Simulink ${ }^{\mathrm{TM}}$ initially using a DSPACE 
Microlabbox ${ }^{\mathrm{TM}}$ board that was also useful to perform preliminary HIL (Hardware In the Loop) and SIL (Software In the Loop) tests.

Figure 12 Preliminary testing activities at Florence University (see online version for colours)
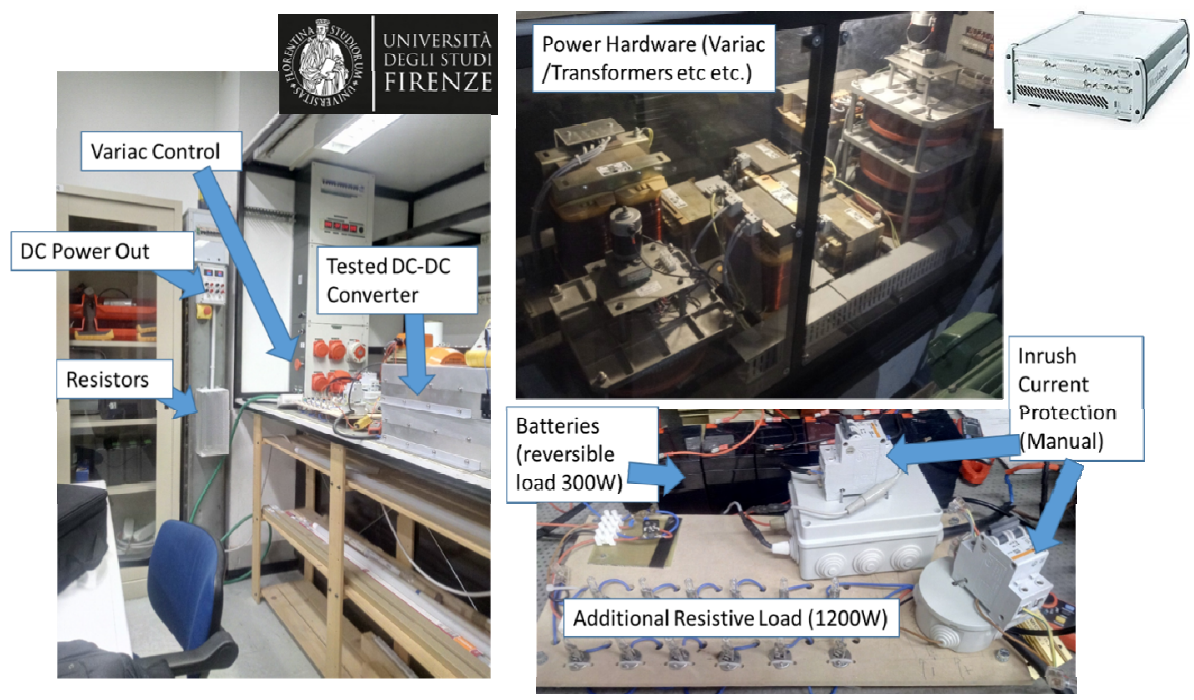

After this preliminary testing activities, the system was assembled according the simplified scheme of Figure 13: vehicle control logic prototyped in Matlab-Simulink ${ }^{\mathrm{TM}}$ was deployed on two Arduino microcontrollers (A); during the flash charge phase microcontrollers are used to activate safety contactors (B), relays (C) and manipulator (D) that controls pantograph run. While vehicle is running, same microcontrollers are used to implement the current loop described in Figure 2: DC-DC converters (E) provide power from supercapacitors to traction systems by measuring battery current with a redundant system of Hall sensors $(\mathrm{H})$. Assembled plant is completed by safety devices such as protection fuses (F) and emergency buttons (I). Additional isolated power supplies $(G, J)$ assure the limited low voltage power needed to supply microcontrollers and auxiliary system.

\subsection{Testing activities in ENEA Casaccia Research Center}

A brief photographic description of the assembled prototype is visible in Figures 14-16. Vehicle prototype was preliminary tested in an internal circuit that was arranged inside the Research Center of ENEA Casaccia in Rome. Vehicle was also instrumented with GPS-GNSS sensors so as visible in Figure 17, it was possible to track vehicle trajectory: vehicle starts its route from the recharge station prototype, performing a mixed route of about $1150 \mathrm{~m}$ which is far higher than the expected vehicle autonomy with supercapacitors; in this way it's possible to verify not only maximum vehicle autonomy, but also to investigate and compare system behaviour system behaviour in nominal 
conditions (capacitors fully charged) with performances in degraded conditions when capacitors are fully discharged and backup batteries have to fully supply the vehicle in order to assure mission survival.

Figure 13 Simplified scheme of the implemented plant (see online version for colours)

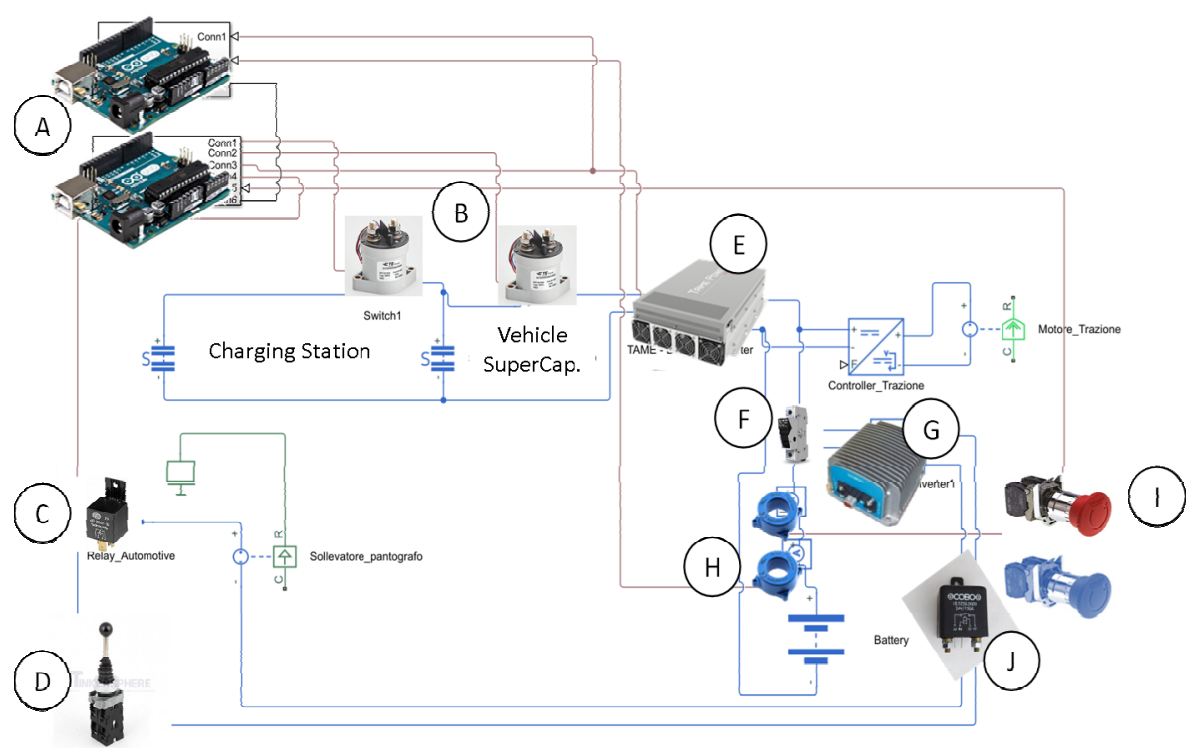

Figure 14 Assembled prototype under the recharge station at ENEA Casaccia Research Center (Italy) (see online version for colours)

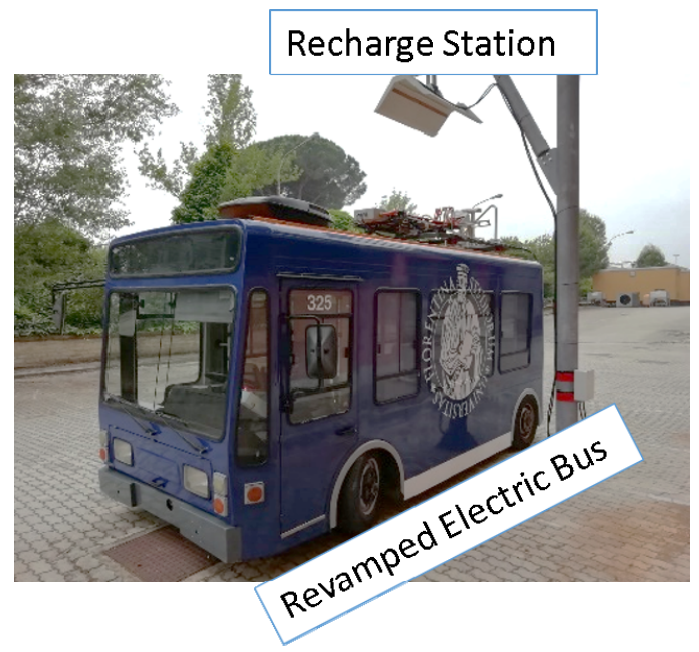

In Figure 18, it's shown a typical speed profile recorded during a mission: vehicle is deliberately accelerated and braked in order to simulate an urban traffic condition stressing the tested system with complex state transition sequences. 
Figure 15 Modular power pack during assembly and installation on the bus (see online version for colours)

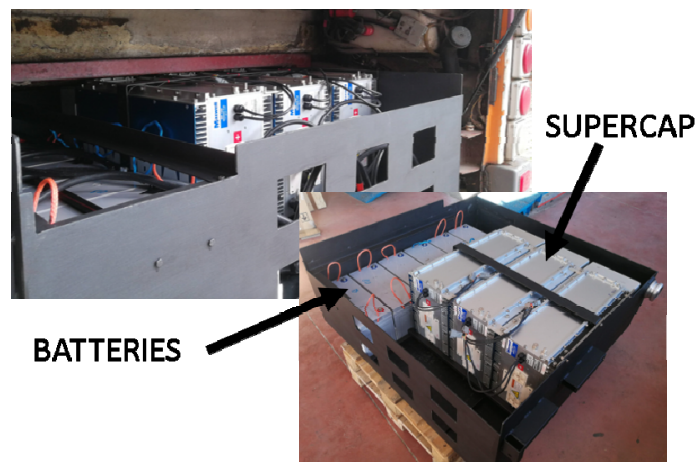

Figure 16 Installed Schunk pantograph on the vehicle (see online version for colours)

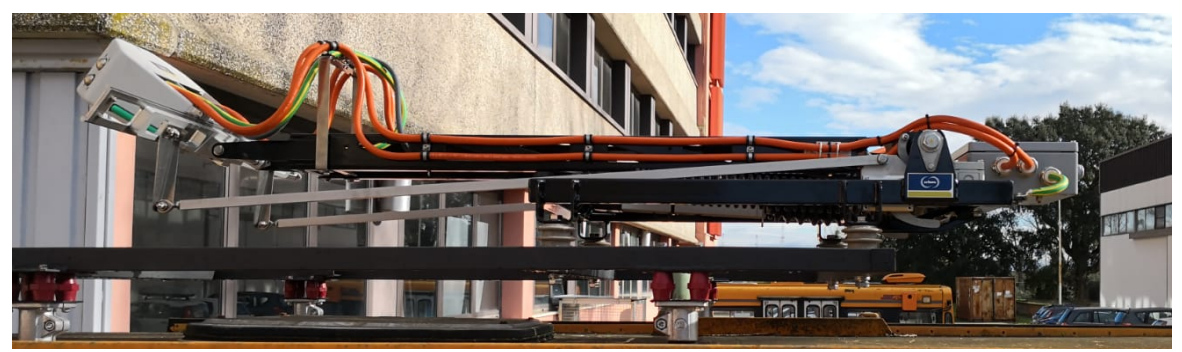

Figure 17 Typical mission profile arranged inside ENEA CASACCIA research centre (see online version for colours)

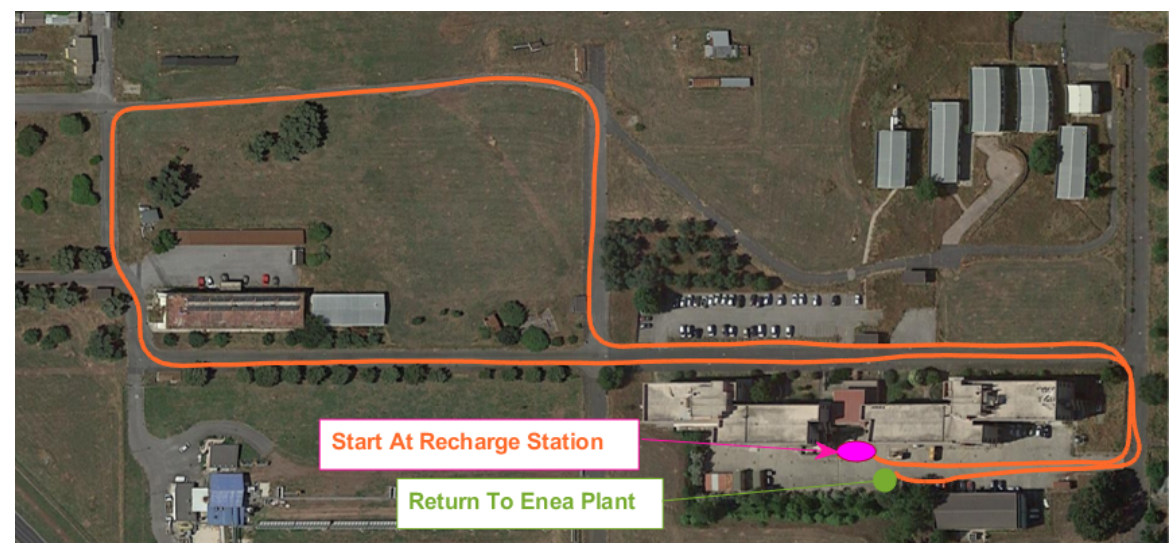

As visible in Figure 19 multiple tests with variable sequences of traction and braking manoeuvres are repeated in order to produce a statistically significant population of different events that are quite useful to test the overall stability of implemented functionalities. 
Figure 18 Example of vehicle speed profile during a mission (see online version for colours)

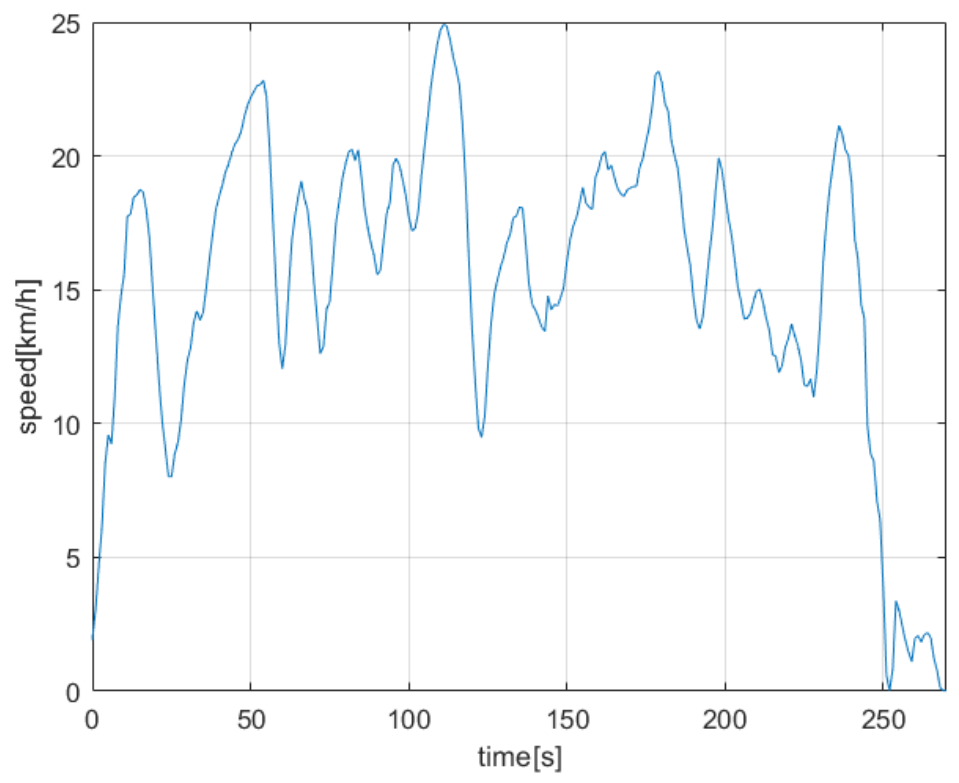

Figure 19 Repeated mission profiles (see online version for colours)

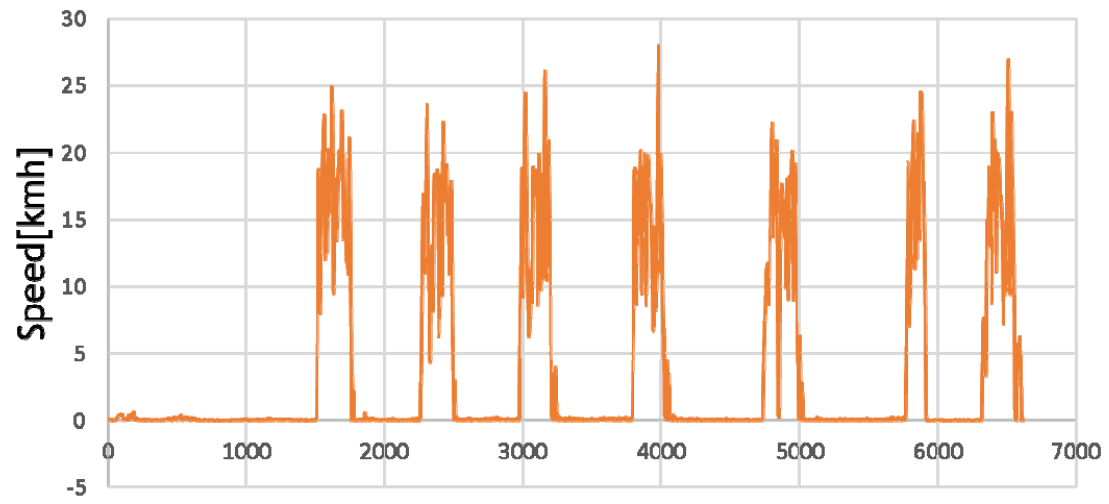

Time[s]

Concerning the power exchanged between vehicle, batteries and supercapacitors during a cycle, some results in terms of exchanged current on vehicle DC bus are shown in Figure 20: it's clearly noticeable that even for the cautious drive style imposed to vehicle during the mission, supercapacitors are able to assist batteries for at least $700 \mathrm{~m}$, which is quite enough respect to previously described specifications.

When supercapacitors are working, they can supply about 60-70\% (corresponding to an equivalent loop gain $K_{p}$ of about 2.5) of the power vehicle demand contributing to drastically reduced loads to which the batteries are subjected.

Looking to results of Figure 20 it's also clear how the good dynamic response of the chosen DC-DC converter contributes to avoid dangerous peak current and more generally assures a quite stable behaviour. 
Figure 20 Example of recorded experimental mission profile (see online version for colours)

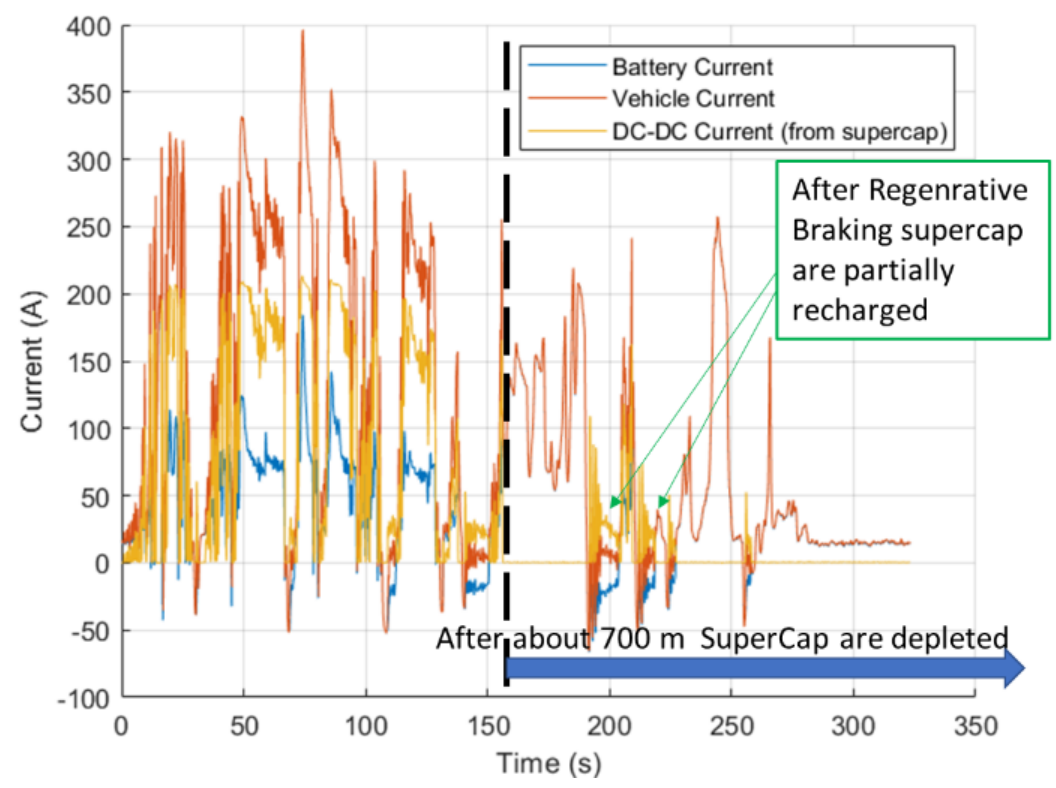

If the mission is longer or more energetically demanding than the expected mean autonomy of $700 \mathrm{~m}$, stored energy in supercapacitors is depleted: supercapacitors can be partially recharged through regenerative braking, also contributing to peak shaving of the battery. However, at the end of the mission capacitors are statistically empty so their capacity can be completely exploited to store energy for the trip to the next bus stop. Concerning the measured efficiency in terms of power transfer between supercapacitors and batteries performed by adopted DC-DC converters, authors executed some measurements of efficiency which are shown in Figure 21: it's interesting to notice that globally recorded efficiency is quite similar to the value declared by the manufacturer even considering noise on measurement and multi-quadrant operation since the converter mainly works as a step down one to feed motor and less frequently as step up to recharge supercap during regenerative braking. Very low level of efficiency is recorded only when transferred power is relatively small respect to the nominal one. In this case efficiency is not only lower but also very variable, probably for the higher influence of measurement noise and of external parameters related to operating conditions (converter mode, supercap voltage etc.). Finally for a georeferenced mission profile, it's possible to know the distance between two consecutive recharge points so it's possible to schedule the gain $K_{p}$ of the current loop in order to better exploit energy stored in capacitors respect to travelled distance. In particular for distances longer than $600-700 \mathrm{~m}$ it should be convenient to reduce the gain while for shorter distances a higher value of gain $K_{p}$ should be useful to further exploit energy stored in super-capacitors. 
Figure 21 Measured efficiency of DC-DC converters respect to expected value (see online version for colours)

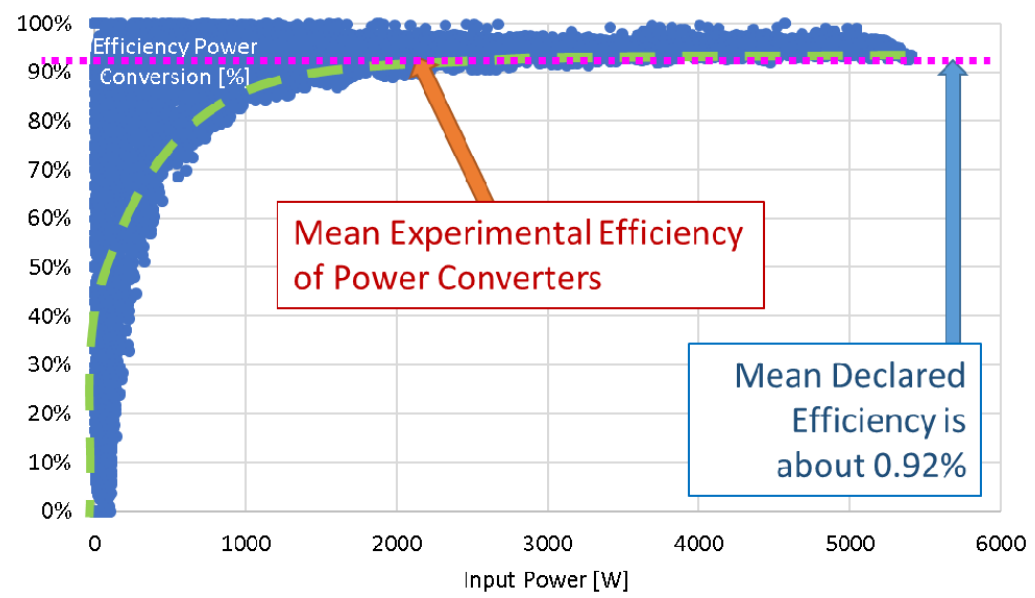

\section{Improved autonomy, reliability and efficiency of batteries}

It's interesting to evaluate the contribution of the system in order to improve battery life and reliability thanks to performed power shaving. This is a quite important feature especially when installed battery is relatively aged resulting in a higher storage impedance. In current prototype, lead batteries are still installed more for a matter of cost of the experimental activity, but in a short term scenario they should be substituted with lithium batteries, in particular in order to have a relatively inexpensive and reliable system, a good candidate in this sense is $\mathrm{Li}[\mathrm{NiCoMn}] \mathrm{O}_{2}$ batteries, briefly called NMC batteries. Also, for these batteries are available in literature (Ceraolo et al., 2018) reliable ageing models also complete calibration data respect to existing and widely used cells. For this reason authors focused their attention considering the possible benefit of applying the proposed system to the same revamped bus in which the existing battery storage is revamped with lithium cells. In particular, the following scenarios are considered:

A Installed lithium battery pack has the same volume as the existing lead acid ones: for considered cells, the new battery pack has about three times more stored energy, $360 \mathrm{Ah}$ vs. the original $120 \mathrm{Ah}$.

B Installed lithium battery pack has the same weight as the existing one: the new battery pack has about 4.87 times more stored energy, $585 \mathrm{Ah}$ vs. the original $120 \mathrm{Ah}$. This value is also more feasible with respect to the original pack of lead acid that was originally placed on the vehicle (595 Ah). Additional volume needed is compatible with current bus layout also considering that thanks to the structural modifications described in Figure 3, the roof of the bus that currently contains only the pantograph can sustain the installation of a large part of on-board subsystems.

Considering these possible scenarios, the same experimental load cycle that is visible in Figure 20 is applied on a Simulink simulation model that reproduces the corresponding 
behaviour of the two battery packs (360/585 Ah) subjected to the same loading cycle. In particular it's considered the application of the cycle at different values of state of charge and of state of health: behaviour of proposed hybrid storage respect to a scenario in which the battery is installed without any help from super-capacitor.

In particular the more interesting scenario is probably the second one (B) since it corresponds to a battery which has almost the same size as the one originally designed for the vehicle.

Looking at results of Figures 22-24 proposed system can approximately double both life and autonomy of installed batteries. Concerning the storage efficiency, application of supercapacitors increases the conversion efficiency of the battery by about $5 \%$. Energy losses due to conversions on supercapacitors are equivalent to about the $8 \%$ but only a half of the total power delivered during the cycle is provided by supercapacitors. Consequently, it should be concluded that the total efficiency of proposed system is higher $(1-2 \%)$ or at least equal to a system with only batteries since the improved efficiency of the battery compensates losses on supercapacitors and converters especially for low values of battery SOC and SOH.

Figure 22 Ratio between battery health losses (B size of 585Ah) for a single loading cycle calculated with proposed hybrid storage and with proposed hybrid storage and with only batteries (see online version for colours)

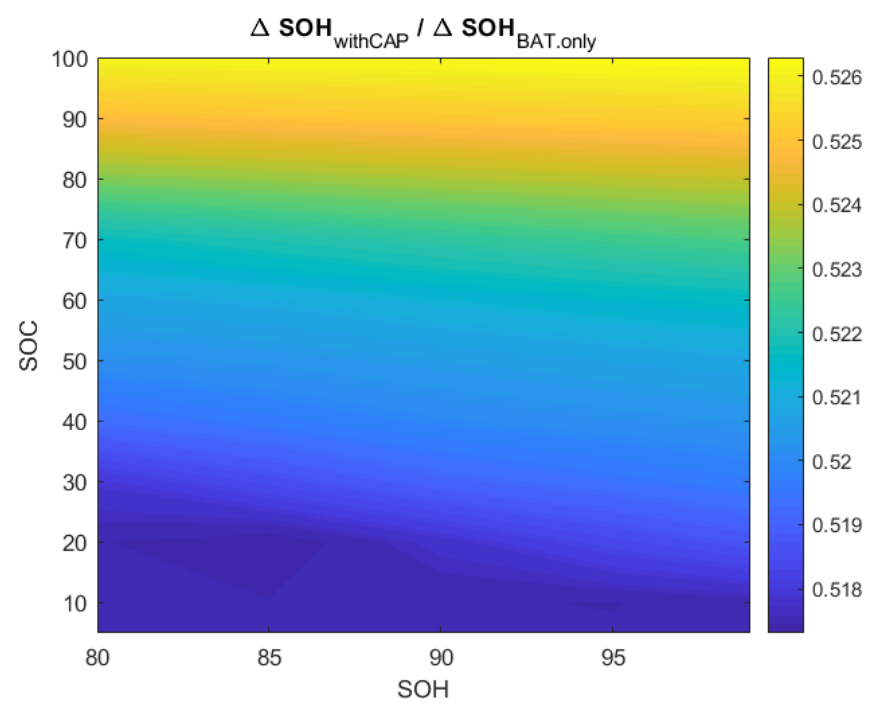

For scenario A the shape of the response in terms of life, reliability and efficiency is quite similar to the ones of Figures 22-24, however the level of the improvement is much higher as expected: in Table 6 mean simulated improvements in terms of expected life, autonomy and efficiency for scenarios A and B are compared; in particular results are referred to a case with a starting SOC of about $50 \%$ and a SOH of $90 \%$ (about half of the foreseen life): for a smaller battery (Case A) relative improvement is obviously higher. 
Figure 23 Ratio between battery state of charge (B size of $585 \mathrm{Ah}$ ) for a single loading cycle calculated with proposed hybrid storage and with proposed hybrid storage and with only batteries (see online version for colours)

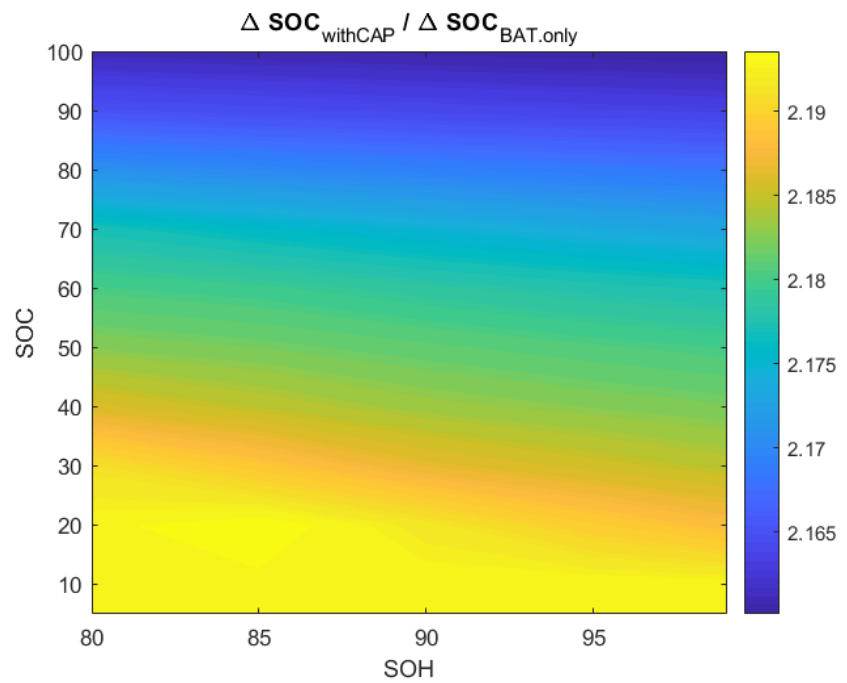

Figure 24 Percentage of efficiency improvement (B size of $585 \mathrm{Ah}$ ) for a single loading cycle calculated with proposed hybrid storage and with proposed hybrid storage and with only batteries (see online version for colours)

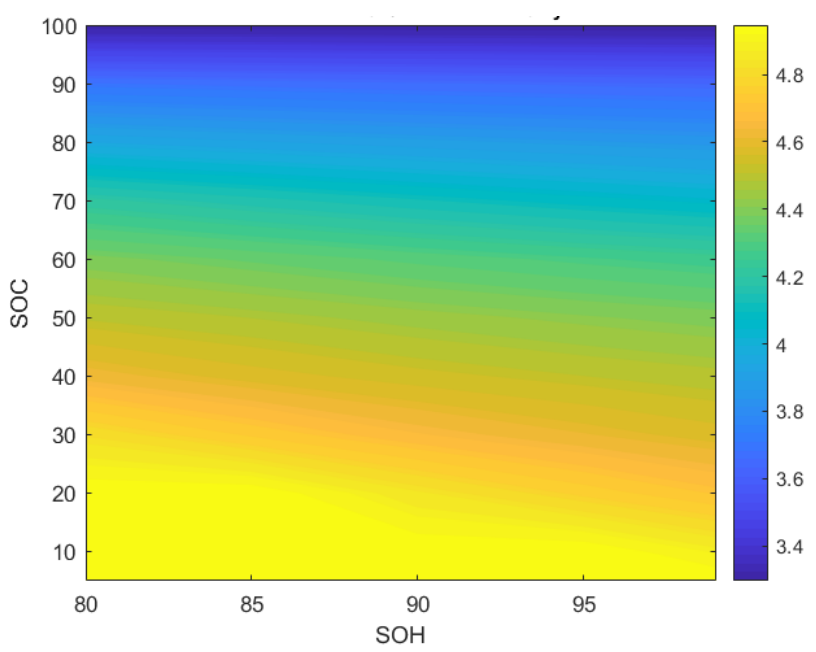

Table 6 Mean estimated improvements in terms of efficiency and reliability

\begin{tabular}{lcc}
\hline Parameter & $\begin{array}{c}\text { Value for Storage A } \\
(360[\mathrm{Ah}])\end{array}$ & $\begin{array}{c}\text { Value for Storage B } \\
(585[\mathrm{Ah}])\end{array}$ \\
\hline \%of Efficiency improvement & $9.92 \%$ & $4.98 \%$ \\
Relative improvement in terms of $\Delta \mathrm{SOH} /$ cycle & 0.4789 & 0.5174 \\
Relative improvement in terms of $\Delta \mathrm{SOC} /$ cycle & 2.335 & 2.194 \\
\hline
\end{tabular}




\section{Conclusions and future developments}

This paper presented the complete development of an innovative flash charge system for urban transport systems. Activities performed on demonstrator vehicle clearly indicate that proposed approach is not only feasible but also easily customisable and optimisable: system can be easily installed also on vehicles which were not originally designed for this purpose. Currently authors are working to the following prosecutions of the proposed works:

- $\quad$ system upgrade to different battery technologies

- integration of the proposed system in a localisation system to perform a mission oriented optimisation of the control logic of the proposed energy management system.

Finally authors are considering the extension of proposed technology to tramways and railway systems exploiting their previous experiences in this field (Pugi et al., 2014, 2018).

\section{Acknowledgements}

This research was funded by Ministero dello Sviluppo Economico, Project C.5, Energy Storage systems for the electric system, PAR 2017.

\section{References}

Barbieri, R., Campatelli, G., Berzi, L., Lapi, M. and Pierini, M. (2016) 'Electric and diesel microbuses driving cycles in firenze city center', EEEIC 2016 - International Conference on Environment and Electrical Engineering, 7-10 June, Florence, Italy, Art. No. 7555601, doi: 10.1109/EEEIC.2016.7555601.

Becker, F. and Dämmig, A. (2016) 'Catenary free operation of light rail vehicles-Topology and operational concept', 2016 18th European Conference on Power Electronics and Applications (EPE'16 ECCE Europe), 5-9 September, IEEE, Karlsruhe, Germany, pp.1-10.

Ceraolo, M., Giglioli, R., Lutzemberger, G., Langroudi, M.M., Poli, D., Andrenacci, N. and Pasquali, M. (2018) 'Experimental analysis of NMC lithium cells aging for second life applications', 2018 IEEE International Conference on Environment and Electrical Engineering and 2018 IEEE Industrial and Commercial Power Systems Europe (EEEIC/I \& CPS Europe), 12-16 June, IEEE, Palermo, Italy, pp.1-6.

Ecker, M., Gerschler, J.B., Vogel, J., Käbitz, S., Hust, F., Dechent, P. and Sauer, D.U. (2012) 'Development of a lifetime prediction model for lithium-ion batteries based on extended accelerated aging test data', Journal of Power Sources, Vol. 215, pp.248-257.

Fernández, I.J., Calvillo, C.F., Sánchez-Miralles, A. and Boal, J. (2013) 'Capacity fade and aging models for electric batteries and optimal charging strategy for electric vehicles', Energy, Vol. 60, pp.35-43.

Hannan, M.A., Hoque, M.M., Mohamed, A. and Ayob, A. (2017) 'Review of energy storage systems for electric vehicle applications: issues and challenges', Renewable and Sustainable Energy Reviews, Vol. 69, pp.771-789.

Musolino, V., Tironi, E. and di Milano, P. (2010) 'A comparison of supercapacitor and high-power lithium batteries', Electrical Systems for Aircraft, Railway and Ship Propulsion, IEEE, 19-21 October, Bologna, Italy, pp.1-6. 
Naumann, M., Karl, R.C., Truong, C.N., Jossen, A. and Hesse, H.C. (2015) 'Lithium-ion battery cost analysis in PV-household application', Energy Procedia, Vol. 73, No. C, pp.37-47.

Ortenzi, F., Pasquali, M., Prosini, P.P., Lidozzi, A. and Di Benedetto, M. (2019) 'Design and validation of ultra-fast charging infrastructures based on supercapacitors for urban public transportation applications', Energies, Vol. 12, No. 12, p.2348.

Pugi, L., Grasso, F. and Rossi, G. (2018) 'Energy simulation of tramway systems, simplified and efficient models', Proceedings - 2018 IEEE International Conference on Environment and Electrical Engineering and 2018 IEEE Industrial and Commercial Power Systems Europe, EEEIC/I and CPS Europe (2018), 12-16 June, Palermo, Italy, Art. No. 8494431, doi: 10.1109/EEEIC.2018.8494431.

Pugi, L., Malvezzi, M. and Conti, R. (2014) 'Optimization of traction and braking subsystems with respect to mission profile', Civil-Comp Proceedings, 15-18 May, Valencia, Spain, p.104.

Veneri, O., Capasso, C. and Patalano, S. (2018) 'Experimental investigation into the effectiveness of a super-capacitor based hybrid energy storage system for urban commercial vehicles', Applied Energy, Vol. 227, pp.312-323.

Yu, H., Tarsitano, D., Hu, X. and Cheli, F. (2016) 'Real time energy management strategy for a fast charging electric urban bus powered by hybrid energy storage system', Energy, Vol. 112, pp.322-331.

\section{Websites}

Complete Tech. Documentation is Available at Maxwell Site, https://www.maxwell.com/ images/documents/125V_Module_datasheet.pdf

Complete Tech. Documentation is Available at TAME Official Site https://www.tamepower.com/en/dc-dc-converters/dcdc-non-isolated-converters

DazeplugTM, Official Company Site, Including Description of Automated Plug Systems https://www.dazetechnology.com/dazeplug/

Official Site of Shunk Company Concerning Fast Recharge Systems for Public Transport Systems, https://www.schunk-carbontechnology.com/en/smart-charging 